\title{
BMJ Open Review of referrals reveal the impact of referral content on the triage and management of ophthalmology wait lists
}

\author{
Vincent Khou (D) , , ${ }^{1,2}$ Angelica Ly (D) , ${ }^{1,2}$ Lindsay Moore, ${ }^{1,2}$ Maria Markoulli, ${ }^{2}$ \\ Michael Kalloniatis, ${ }^{1,2}$ Michael Yapp, ${ }^{1,2}$ Michael Hennessy (D) ,1,3 Barbara Zangerl ${ }^{2,4}$
}

To cite: Khou V, Ly A, Moore L, et al. Review of referrals reveal the impact of referral content on the triage and management of ophthalmology wait lists. BMJ Open

2021;11:e047246. doi:10.1136/ bmjopen-2020-047246

- Prepublication history and additional supplemental material for this paper are available online. To view these files, please visit the journal online (http://dx.doi.org/10.1136/ bmjopen-2020-047246).

Received 23 November 2020 Accepted 25 August 2021

D) Check for updates

(c) Author(s) (or their employer(s)) 2021. Re-use permitted under CC BY-NC. No commercial re-use. See rights and permissions. Published by BMJ.

${ }^{1}$ Centre for Eye Health, Sydney, New South Wales, Australia ${ }^{2}$ School of Optometry and Vision Science, Faculty of Medicine and Health, University of New

South Wales, Sydney, New South Wales, Australia

${ }^{3}$ Department of Ophthalmology, Prince of Wales Hospital, Sydney, New South Wales, Australia

${ }^{4}$ Coronary Care Unit, Royal

Prince Alfred Hospital, Sydney, NSW, Australia

Correspondence to

Dr Barbara Zangerl;

zangerlb@gmail.com

\section{ABSTRACT}

Objectives Many chronic eye conditions are managed within public hospital ophthalmology clinics resulting in encumbered wait lists. Integrated care schemes can increase system capacity. In order to direct implementation of a public hospitalbased integrated eye care model, this study aims to evaluate the quality of referrals for new patients through information content, assess triage decisions of newly referred patients and evaluate the consistency of referral content for new patients referred multiple times.

Design A retrospective and prospective review of all referral forms for new patients referred to a public hospital ophthalmology clinic between January 2016 and September 2017, and September 2017 and August 2018, respectively. Setting A referral-only public hospital ophthalmology clinic in metropolitan Sydney, Australia.

Participants 418 new patients on existing non-urgent wait lists waiting to be allocated an initial appointment, and 528 patients who were newly referred.

Primary and secondary outcome measures The primary outcome was the information content of referrals for new patients. The secondary outcomes were triage outcomes for new incoming referrals, and the number of new patients with multiple referrals.

Results Of the wait-listed referrals, $0.2 \%$ were complete in referral content compared with $9.8 \%$ of new incoming referrals $(p<0.001)$. Of new incoming referrals, $56.7 \%$ were triaged to a non-urgent clinic. Multiple referrals were received for 49 patients, with no change in the amount of referral content.

Conclusions Most referrals were incomplete in content, leading to triage based on limited clinical information. Some new patients were referred multiple times with their second referral containing a similar amount of content as their first. Lengthy wait lists could be prevented by improving administrative processes and communication between the referral centre and referrers. The future implementation of an integrated eye care model at the study setting could sustainably cut wait lists for patients with chronic eye conditions.

\section{INTRODUCTION}

Increasing life expectancy and declining fertility rates worldwide have resulted in an ageing population. ${ }^{1}$ Concurrently,
Strengths and limitations of this study

- This study reviewed all referrals for new patients to a public hospital eye clinic, regardless of the ocular condition for which they were referred. A condition of inclusion was that an initial appointment had not yet been made.

- This study was also able to identify the number of patients who had been referred to a public hospital eye clinic multiple times but were yet to receive an initial appointment at the clinic.

- This study did not measure the wait time between the receipt of referral and date of the patient's initial appointment as an outcome.

- As reasons for referral were categorised within four groups, the number of patients referred for a second time may have been underestimated.

- The categorisation of referrers by their profession meant that repeat referrals from another practitioner within the same profession were not captured in the data.

contemporary lifestyle choices have contributed to the prevalence of chronic health conditions in the elderly. ${ }^{2}$ This includes chronic, progressive eye disorders, which are increasingly prevalent with age. ${ }^{3}$ These disorders typically require periodic follow-up to reassess risk status, establish diagnosis, manage progression and prevent potential complications, ${ }^{4}$ creating a burden on healthcare systems.

Many chronic eye conditions are managed within public hospital outpatient and inpatient settings. Consequently, wait lists for clinic visits are an ongoing challenge in publicly funded healthcare systems. $^{5-7}$ Increasing demands on public healthcare systems can reduce capacity for new patient intake, which, if not managed, impedes timely and appropriate access to services. For example, patients referred for cataract surgery compete for limited capacity, resulting in waits of over 
a year for an initial public hospital outpatient clinic assessment, ${ }^{8}$ prior to then being placed on the elective surgery wait list.

Several models for the care and management of chronic eye disorders have been examined using referral refinement and/or collaborative care schemes ${ }^{5-13}$ and have been shown to increase system capacity. ${ }^{13}$ In order to inform future implementation of a novel hospital-based integrated care model that sustainably reduces wait lists, an assessment of wait-listed referrals is required. ${ }^{14}$

Research regarding referral quality has generally explored the appropriateness of referrals to specialists by examining the diagnostic accuracy of referrals as well as interventions to improve referral appropriateness. ${ }^{10} 15-19$ Referral quality has also been assessed through the completeness of referral content. ${ }^{19-23}$ It is important to recognise that not all the information on referrals may be required for triage. For example, referrals providing either a presumed diagnosis or observed signs or symptoms may be sufficient for appropriate triage. Notwithstanding, all information provided in a referral could be insufficient for triage if the information is incorrect. Hence, diagnostic accuracy and completeness of referral content both affect the appropriate triage of patients. In particular, the improper categorisation of high-risk patients as non-urgent and vice versa, delays appropriate patient management, resulting in poorer outcomes. ${ }^{24}$ Additionally, patients who are referred with incomplete referrals can experience longer wait times than those referred with more complete referrals as they may be perceived as less urgent. ${ }^{25}$ Lengthy wait lists can also cause the content of interminably queued referrals to become outdated. ${ }^{6}$ Referral quality may differ depending on the referrer's profession ${ }^{8}$ and referral format, ${ }^{26}$ and standardised referral templates can mitigate such issues. ${ }^{6}$

This study aims to scrutinise wait-listed referrals at a metropolitan public eye clinic by determining the quality of referrals for new patients, assess triage decisions and evaluate the consistency of referrals for new patients referred multiple times.

\section{METHODS}

\section{Patient and public involvement}

Patients and the public were not involved in the design and conduct of this study.
Prince of Wales Hospital Eye Clinic triage protocol and appointment process

Referrals at the Prince of Wales Hospital (POWH) Eye Clinic are currently triaged by an on-site ophthalmic nurse. Referrals reporting acute changes such as loss of vision, and red or painful eye; or indicating sightthreatening or life-threatening conditions, such as retinal detachment, orbital cellulitis or giant cell arteritis, are triaged as requiring urgent attention. If the referral is classified as non-urgent, the patient is placed on a nonurgent wait list. Otherwise, the patient is booked in for an appointment within a 6-month time frame. Wait lists for new patients are managed separately from returning patients. Returning patients are independently contacted and scheduled for the appropriate follow-up visits, which are prioritised over initial, non-urgent appointments for new patients.

\section{Study design}

For the study, referrals were evaluated from three different scenarios: existing wait list referrals (set A), new incoming referrals (set B) and patients with multiple referrals (set C). Set A was drawn from the list of outstanding referrals that remained on the wait list for an appointment for new patients as of the 26t September 2017. Set B was drawn from all referrals received for new patients from the 26 September 2017 to the 27 August 2018.

\section{Set A: existing wait list referrals}

A retrospective analysis was performed on referrals as outlined in table 1 . The review period was left open to ensure all referrals on the existing wait list were reviewed. Referrals for patients over the age of 18 , and patients not under institutional or correctional care were included. The following referrals were excluded: (1) current or returning patients at all public hospital ophthalmology clinics within the same local health district (LHD), (2) patients who were found to already have a booked future appointment at the POWH Eye Clinic, which arose from referrals not being removed from the wait list for an appointment, (3) patients where the referral was inaccessible and (4) the patient was deceased since being referred. Referrals were only excluded once all referrals in set A were collated, and this was performed immediately prior to the commencement of data analysis. Data analysis for set A commenced on the 10 August 2017,

Table 1 Characteristics of the referral sets

\begin{tabular}{|c|c|c|c|}
\hline & Set A: Existing wait list referrals & Set B: New incoming referrals & Set C: Multiple referrals \\
\hline Appointment status & $\begin{array}{l}\text { New patients with no appointment } \\
\text { scheduled }\end{array}$ & $\begin{array}{l}\text { New patients with newly triaged } \\
\text { referrals }\end{array}$ & $\begin{array}{l}\text { New patients referred at least } \\
\text { twice }\end{array}$ \\
\hline Triage status & $\begin{array}{l}\text { Contains referrals triaged non-urgent } \\
\text { only }\end{array}$ & $\begin{array}{l}\text { Referrals triaged urgent and non- } \\
\text { urgent }\end{array}$ & $\begin{array}{l}\text { Referrals triaged urgent and non- } \\
\text { urgent }\end{array}$ \\
\hline
\end{tabular}


which was 2 weeks after the date for which referrals for set A were drawn. The resultant set of referrals represented new patients who were on the existing non-urgent clinical appointment wait list.

\section{Set B: new incoming referrals}

Since set A referrals were only representative of nonurgent referrals received by the POWH Eye Clinic, urgent referrals to the clinic were not captured in the retrospective analysis. Hence, a prospective analysis was also performed on referrals as outlined in table 1 . The analysis was conducted for referrals dated between the 26 September 2017 and 27 August 2018. The same inclusion and exclusion criteria as applied to set A were used. Since referrals in set B were prospectively collected, the criteria were applied within 1 week after the referrals were forwarded to us by the POWH Eye Clinic. Referrals were forwarded by the POWH Eye Clinic within 1 week of the referral being received by the clinic. Hence, the analysis for each referral occurred 2 weeks after receipt of the referral by the POWH Eye Clinic. The resultant set of referrals represented newly referred patients.

\section{Set C: multiple referrals}

When patients with multiple referrals were identified from sets $\mathrm{A}$ and $\mathrm{B}$, the initial referral remained in set $\mathrm{A}$ and $\mathrm{B}$ for analysis and was included in set $\mathrm{C}$ for subanalysis. Subsequent referrals for the corresponding patient were excluded from sets A and B and included in set $\mathrm{C}$.

\section{Data extraction and refinement}

For all referral sets, the following data were collected for analysis: patient demographics, referrer profession, primary reason for referral, best-reported visual acuity (VA) in the worse eye, signs and/or symptoms, specified urgency by the referrer, referral format used and triage decision.

The primary reason for referral was categorised by author LM as relating to anterior eye, cataract, general examination or posterior eye. The first reason listed was categorised if multiple reasons were provided. Referrers were classified by profession. Reporting of an urgency and VA were classified as present or absent. If VA was reported, it was classified as: better than $6 / 12$, between $6 / 12$ and better than $6 / 60$ or 6/60 and worse. Reporting of signs/ symptoms was categorised as: present, diagnosis reported only or absent. Referral format was categorised as handwritten letter, POWH Eye Clinic template or computer generated. Triage decision, which was written on the referral, was grouped by: seen within 1 month, seen within 3-6 months, seen within 6-12 months, general clinic nonurgent, cataract clinic non-urgent, specific doctor's clinic or rejected. Referrals that were triaged as seen within 6-12 months, general clinic non-urgent or cataract clinic nonurgent were considered to be non-urgent. ${ }^{27}{ }^{28}$ Referrals that had been triaged to be seen with 3-6 months were defined as semiurgent. ${ }^{27}{ }^{28}$ Urgent referrals were defined as those requiring an appointment within 1 month. ${ }^{27-29}$

\section{Statistical analysis}

Statistical analyses were performed with SPSS (V.25, IBM) and Graphpad Prism (V.8, Graphpad, San Diego, USA). Demographic variables analysed included age, gender and location of residence (derived from postcode). Referrals were considered complete in information if primary reason for referral, VA, signs/symptoms and reported urgency were all included in the referral. Referrals with missing data were not excluded as referral completeness was an outcome. One-way analysis of variance was used to assess significant differences in age. Fisher's exact test was used to ascertain statistical differences in categorical data, with additional post hoc analyses conducted using the partitioning method if significant. ${ }^{30}$ McNemar's test and marginal homogeneity test were used to determine whether the amount of content provided in paired referrals in Set $\mathrm{C}$ changed. Values of $\mathrm{p}<0.05$ were considered significant except for when a Bonferroni correction to the significance level $(\alpha)$ was applied for post hoc analyses.

\section{RESULTS}

Each set of referrals represented new individual cases to the clinic and encompassed different characteristics (table 1).

\section{Set A: existing wait list referrals}

A total of 1633 patients were on the wait list to be scheduled for an initial appointment. The following referrals were excluded: 649 (39.7\%) were for returning patients awaiting recall, $32(2.0 \%)$ could not be traced, $44(2.7 \%)$ were multiple referrals and put aside for set C, $474(29.0 \%)$ were for patients with already completed or scheduled appointments, three $(0.2 \%)$ were for now-deceased patients and $13(0.8 \%)$ were for patients under guardianship. Subsequently, referrals for 418 new patients were analysed. It was found that these referrals corresponded to a period spanning from 23 January 2016 to 25 September 2017.

\section{Set B: new incoming referrals}

A total of 539 new patient referrals were received during the review period. Of these, 11 referrals were categorised as repeat referrals and were excluded from the original data set and separately analysed to form for set C. All other referrals met the exclusion criteria resulting in a total of 528 referrals.

\section{Set C: multiple referrals}

Forty-nine patients were referred multiple times, with 43 referred twice, 5 referred three times and 1 referred four times. Only second referrals were compared with initial referrals due to the small numbers of third and fourth referrals.

\section{Patient demographics}

The demographics of the patients were similar in all analysed sets of referrals (table 2). The number of referrals from general practitioners (GPs) and optometrists were 
Table 2 Demographics and referrer profession of patients referred to the Prince of Wales Hospital Eye Clinic

\begin{tabular}{|c|c|c|c|c|}
\hline & $\begin{array}{l}\text { Set } A \text { : Existing wait list } \\
\text { referrals }(n=418)\end{array}$ & $\begin{array}{l}\text { Set B: New incoming } \\
\text { referrals }(n=528)\end{array}$ & $P$ value & Post hoc analysis* \\
\hline Mean age, years (SD) & $65.3(14.5)$ & $66.3(15.7)$ & 0.33 & - \\
\hline LHD, n (\%) & & & 0.10 & - \\
\hline SESLHD & $326(78.0)$ & $423(80.9)$ & & \\
\hline Referrer profession, n (\%) & & & 0.02 & 1.vs 3. $P=0.008$ \\
\hline 1.General practitioner & $190(45.4)$ & $214(40.5)$ & & \\
\hline 2.Optometrist & $184(44.0)$ & $227(43.0)$ & & \\
\hline 3.Othert & $44(10.5)$ & $87(16.4)$ & & \\
\hline
\end{tabular}

*Post hoc $\alpha$ was Bonferroni corrected to 0.017 . Only significant $p$ values shown. †Other included ophthalmologists and intrahospital referrals.

LHD, local heath district; SESLHD, South Eastern Sydney Local Health District.

similar between sets A and B ( $\mathrm{p}=0.53)$. The proportion of patients referred from outside the LHD was also similar $(\mathrm{p}=0.10)$, with $19.0 \%$ (179) of all patients residing in another metropolitan LHD.

\section{Quality of referral content of set A and B}

Overall, $0.2 \%$ (one referral) of set A referrals and $9.8 \%$ (52 referrals, $\mathrm{p}<0.001$ ) of set $\mathrm{B}$ referrals had a complete set of information. The information provided in referrals is presented in table 3 . Only the presence of an urgency was significantly different between set A and set $B(p<0.001)$. A reason for referral was provided in all referrals.

Subgroup analyses were subsequently performed and are presented in online supplemental materials. Cataract was the main reason for referral for both GPs and optometrists (online supplemental table 1). Rates of reporting VA were lower for GPs compared with optometrists in both sets (both $\mathrm{p}<0.001, \alpha$ was Bonferroni corrected to 0.017). GPs reported more often on diagnoses over signs/ symptoms compared with optometrists in both sets (both $\mathrm{p}<0.001, \alpha$ was Bonferroni corrected to 0.017). Referrals from optometrists that reported both signs/symptoms and diagnosis were not significantly different between the two sets. Overall, $90.2 \%$ (371 referrals) of referrals from optometrists contained both signs/symptoms and a diagnosis.

Since no statistically significant difference was found for referral format, reporting of VA and signs/symptoms, the data for Sets A and B were pooled for analysis. A sign/symptom and a diagnosis were listed more often in the POWH Eye Clinic template $(98.0 \%)$ compared with computer-generated referrals $(88.3 \%)(\mathrm{p}<0.001, \alpha$ was Bonferroni corrected to 0.017 , (online supplemental table 2). VA was listed more frequently in the POWH Eye Clinic template compared with computer-generated referrals and handwritten letters $(84.9 \%$ and $35.9 \%$, $\mathrm{p}<0.001$; and $57.3 \%, \mathrm{p}<0.001$; Bonferroni corrected $\alpha$ was adjusted to 0.017 ) and listed more often in handwritten letters over computer-generated referrals $(\mathrm{p}<0.001$; $\alpha$ was Bonferroni corrected to 0.017).

\section{Triage outcomes of referrals}

All referrals from set A were triaged as 'general clinic non-urgent' (418 referrals). The triage decisions for set

\begin{tabular}{|c|c|c|c|}
\hline & $\begin{array}{l}\text { Set A: } \\
\text { Existing wait } \\
\text { list referrals }\end{array}$ & $\begin{array}{l}\text { Set B: New } \\
\text { incoming } \\
\text { referrals }\end{array}$ & $P$ value \\
\hline Reason for referral, n (\%) & & & 0.10 \\
\hline Anterior eye & 75 (17.9) & $93(17.6)$ & \\
\hline Cataract & $201(48.1)$ & $253(47.9)$ & \\
\hline General examination & $39(9.3)$ & $55(10.4)$ & \\
\hline Posterior eye & $103(24.6)$ & $127(24.1)$ & \\
\hline Absent & $0(0.0)$ & $0(0.0)$ & \\
\hline Visual acuity, n (\%) & & & 0.19 \\
\hline Present & $191(45.7)$ & 265 (50.2) & \\
\hline Absent & $227(54.3)$ & $263(49.8)$ & \\
\hline Signs or symptoms, n (\%) & & & 0.96 \\
\hline Present & $271(64.8)$ & $347(65.7)$ & \\
\hline Diagnosis reported only & $109(26.1)$ & $134(25.4)$ & \\
\hline Absent & $38(9.1)$ & $47(8.9)$ & \\
\hline Urgency, n (\%) & & & $<0.001$ \\
\hline Present & $11(2.6)$ & $77(14.6)$ & \\
\hline Absent & $407(97.4)$ & $451(85.4)$ & \\
\hline Referral format, n (\%) & & & 0.28 \\
\hline Handwritten letter & $36(8.6)$ & $39(7.4)$ & \\
\hline $\begin{array}{l}\text { POWH Eye Clinic } \\
\text { template }\end{array}$ & $81(19.4)$ & $124(23.5)$ & \\
\hline Computer-generated & $301(72.0)$ & $365(69.1)$ & \\
\hline
\end{tabular}

POWH, Prince of Wales Hospital. 
Table 4 Triage decisions of new incoming referrals (set B) at the Prince of Wales Hospital Eye Clinic and the presence of an urgency in these referrals

\begin{tabular}{|c|c|c|c|c|}
\hline & Urgency present & Urgency absent & $P$ value & Post hoc analysis* \\
\hline 1. Within 1 month & $20(25.0)$ & $60(75.0)$ & & 1. vs 3. $p=0.56$ \\
\hline 3. 6-12 months & $0(0.0)$ & $4(100.0)$ & & 1. vs $5 . p=0.05$ \\
\hline 4. General clinic non-urgent & $12(9.5)$ & $114(90.5)$ & & 1. vs 6. $p<0.001$ \\
\hline 6. Specific doctor's clinic & $3(4.5)$ & $64(95.5)$ & & \\
\hline 7. Rejected & $0(0.0)$ & $8(100.0)$ & & \\
\hline
\end{tabular}

${ }^{*}$ Post hoc $\alpha$ was Bonferroni corrected to 0.0024 . Only significant $p$ values and select non-significant $p$ values shown. Significant $p$ values are in bold.

B referrals are listed in table 4. Overall, 56.7\% (299 referrals) were triaged to a non-urgent clinic. The presence of an urgency in new incoming referrals resulted in a significant difference in triage decisions $(p<0.001)$, however, post hoc analyses revealed that there were no significance differences in referrals triaged 'within 1 month' compared with those triaged '3-6 months', '6-12 months', 'general clinic non-urgent' and 'cataract clinic non-urgent' ( $\mathrm{p}>0.99, \mathrm{p}=0.56, \mathrm{p}=0.005, \mathrm{p}=0.05$, respectively, $\alpha$ was Bonferroni corrected to 0.0024). Subgroup analyses indicated that for referrals triaged to a non-urgent category, $8.4 \%$ (25 referrals) did not provide a sign/symptom or diagnosis, and $48.5 \%$ (145 referrals) did not provide a VA. For referrals triaged to be seen within 1 month, $57.5 \%$ (46 referrals) did not provide a VA, 30.0\% (24 referrals) had vision better than $6 / 12$ (online supplemental table 3 ) and $16.3 \%$ (13 referrals) did not provide a sign/symptom or diagnosis.

\section{Content of referrals for patients referred multiple times}

The mean time between first and second referrals was $141 \pm 175$ days, and $15(30.6 \%)$ second referrals were sent within 7 days after the first. The reporting of VA, signs/ symptoms, and an urgency did not change between referrals (table 5). The referrer's profession was different between paired referrals in $51.0 \%$ of cases (25 referrals, $\mathrm{p}<0.001$ ), although we were unable to discern changes in practitioner within the same profession. The reason for referral changed for $46.9 \%$ (23 referrals, $\mathrm{p}<0.001$ ) of patients. The triage decision changed in $40.8 \%$ (20 referrals, $\mathrm{p}<0.001)$ of cases. Of the patients who were referred for the same reason on the second occasion, $37.2 \%$ (16 referrals) were triaged differently.

\section{DISCUSSION}

This study found that referrals for new patients reported on an urgency, VA and signs/symptoms to varying degrees, with little reporting on all three. Wait lists were inflated by referrals for patients with already completed or scheduled appointments, and by repeat referrals. For patients who were referred for a second time, the amount of content in both referrals was similar, but patients were referred for different reasons.

\section{Suboptimal information content affects triage}

Suboptimal information content can subvert the triage process, ${ }^{31}$ and in this study, a minority of referrals were found to be complete in information content. Yet, incomplete referrals are deemed to be acceptable by the ophthalmic nurse to triage. The interpretation of such requires significant experience and/or a level of triage training, ${ }^{32}$ where inexperience can lead to a reluctance in rejecting referrals, and thus having to adapt to low information content risks less precise triage and inconsistencies. Thus, it is vital that referrals contain information including VA, signs/symptoms and urgency. Symptoms indicate the functional impacts of conditions and VA is a fundamental component of the degree of visual impairment thereby dictating referral priority, even with nonurgent cases. For example, VA can decrease by two lines and three letters over a period of 13 months in patients who are wait listed for cataract, ${ }^{33}$ and those with worse

Table 5 Referral content between the first and second referral

\begin{tabular}{lccc}
\hline & First referral & $\begin{array}{l}\text { Second } \\
\text { referral }\end{array}$ & P value \\
\hline $\begin{array}{l}\text { Visual acuity, } \mathrm{n}(\%) \\
\text { Present }\end{array}$ & $24(49.0)$ & $17(34.7)$ & 0.19 \\
$\begin{array}{l}\text { Absent } \\
\text { Signs or symptoms, } \mathrm{n}(\%)\end{array}$ & $32(65.3)$ & \\
$\begin{array}{l}\text { Present } \\
\text { Diagnosis } \\
\text { reported only }\end{array}$ & $38(77.6)$ & $30(61.2)$ & 0.07 \\
$\begin{array}{l}\text { Absent } \\
\text { Urgency, } \mathrm{n}(\%)\end{array}$ & $3(16.3)$ & $12(25.4)$ & \\
\hline $\begin{array}{l}\text { Present } \\
\text { Absent }\end{array}$ & $2(4.1)$ & $7(14.3)$ & \\
\hline
\end{tabular}


reported VA are generally prioritised. In the case of urgency, referrers may be unable to triage urgency and expect that the hospital would determine implied referral priority from VA and signs/symptoms. The implementation of referral templates has resulted in good-quality referrals in other specialty fields. ${ }^{34}$ While the clinic's referral template provided a prompt for VA and signs/ symptoms, it was not widely used. Simply informing referrers of hospital wait times for assessment is enough to encourage uptake of referral templates. ${ }^{35}$

\section{Causes of lengthy wait lists}

The analysis of the electronic wait list revealed that almost three-quarters of referrals did not require an initial appointment, consequently inflating the wait list. These were referrals where (1) the patient was deceased, (2) already under the care of the clinic and (3) already allocated an appointment, which were not being withdrawn from the wait list. This indicates a lack of a process for referrals to be withdrawn when no longer needed. Consequently, the number of patients on the wait list was inflated by administrative problems in managing appointments when given and in not being notified when the appointment was no longer needed. Improvements in waiting times can be expected from improved administrative processes, or reassessment of referrals on the wait list for appropriateness after an extended period can ameliorate this. ${ }^{6}$ Moreover, interim optometric examinations to revise the information provided in referrals and/ or possibly determine the need for the hospital visit can also reduce wait lists.

Reasons for referral changed in almost half of patients who were referred for a second time and were received from a different profession in half of the patients. Almost one in three repeat referrals were received a week after the first referral. This could indicate that information in a patient's referral needed revision because of the wait to be seen, or patients themselves seeking a different referring practitioner for another opinion who knowingly or unknowingly refers again. These scenarios highlight a need for improved communication and feedback among the patient's relevant health professionals and the POWH Eye Clinic ${ }^{36}$ including confirmation of receipt of referrals, an indication of wait times, efforts to reduce unnecessary repeat referrals, and in some cases alternative assessments with an optometrist, to better target the provision of service and at the same time decrease wait time.

A proportion of patients referred to the POWH Eye Clinic resided outside of its respective LHD. Each metropolitan LHD within New South Wales, Australia is serviced by at least one of ten tier 2 adult outpatient ophthalmology clinics located within Sydney. The POWH Eye Clinic is one of three clinics that does not actively discourage referrals for patients residing outside of its respective LHD, but recommends the use of similar services within a patient's respective LHD. ${ }^{37}$ The intake of out-of-area patients can add to wait lists for an appointment, however, this could be a flow-on effect from wait lists in other LHDs. ${ }^{8}$ We were unable to determine how many patients sought care simultaneously in multiple LHDs, who then accept the first appointment they are offered, while not necessarily cancelling their request at other LHDs.

\section{Strengths and limitations}

A strength of this study was that it included all referrals of new patients to the POWH Eye Clinic, regardless of the primary reason for which they were referred. Other studies examining wait lists have typically examined referrals to eye clinics for a single condition, ${ }^{7838-40}$ thereby neglecting referrals for other ocular conditions which would also add to the wait lists for referral-only eye clinics. Furthermore, this study examined the backlog of existing referrals for new patients already placed on the wait list, which only contained non-urgent referrals, as well as new incoming referrals for new patients, which included urgent and non-urgent referrals. By doing so, we were able to assess whether the information content of referrals differed between these two sets of referrals. Moreover, we could also track the number of new patients for whom multiple referrals had been received over the review period.

There are several limitations to this study. Referrals in set A, by design, were heavily biased towards nonurgent referrals, and therefore, would not be representative of all referrals received by the POWH Eye Clinic. However, this was addressed with the inclusion of referrals in set B which represented all new incoming referrals and included urgent referrals. Subsequently, there was only a significant difference in referrals reporting on an urgency, which we could conclude was caused by the inclusion of urgent referrals as a part of set B. At the same time, for set B, we were unable to ascertain whether all referrals had been forwarded from the POWH Eye Clinic. The reasons for referral were also categorised into four overarching groups, which as a result, may underestimate the number of patients who were referred a second time under a different reason. An overestimation may also have occurred since secondary reasons for referral were not collected during this study and therefore matching reasons may have been missed. In addition to this, the classification of referrers by profession meant that second referrals from a different practitioner within the same profession were not represented in the data. Unlike other studies, this study did not investigate the wait times experienced by new patients, ${ }^{8}{ }^{38-40}$ as these patients did not have an allocated appointment at the time of our referral review. Similarly, as these patients had not been examined by the POWH Eye Clinic, this study was not able to assess the diagnostic accuracy of referrals. Within the context of this study, referral quality was, therefore, limited to assessing completeness of referral content, even though it could be evaluated through the diagnostic accuracy of referrals. ${ }^{15}{ }^{16}$ Consequently, referrals that are fully completed can still incur inappropriate patient triage if 
the content of the referral, especially the diagnosis, is insufficient, inaccurate or incorrect.

\section{CONCLUSION}

In conclusion, referrals to the POWH Eye Clinic were largely incomplete in content leading to triage decisions being made in many cases based on limited clinical information. Referral templates can help prompt for more information being provided and their consistent use can be expected to improve triage. Improved communication among the hospital and referrers needs to be addressed to prevent prolonged wait lists. The quantity of referrals on wait lists uncovered by this study justifies the need to develop an integrated care model to cut wait lists. Future work is now underway to determine the effectiveness of alternative models for assessment of patients facing long waits when their complaint is triaged to a non-urgent appointment category.

Acknowledgements The authors would like to acknowledge Zoe Schrire and Sean Sivieng for work pertaining to data acquisition.

Contributors VK was involved in drafting of the manuscript, data analysis and data interpretation. AL was involved in critical review of the manuscript, data analysis and data interpretation. LM was involved in critical review of the manuscript, data analysis and data interpretation. MM was involved in critical review of the manuscript and data interpretation. MK was involved in critical review of the manuscript and data interpretation. MY was involved in critical review of the manuscript and conception. MH was involved in critical review of the manuscript and conception. BZ was involved in critical review of the manuscript, conception, data analysis and data interpretation.

Funding VK is supported by the Australian Government through the Research Training Programme (RSAP1000). Guide Dogs NSW/ACT provides support for the Centre for Eye Health, salary support for AL, LM, MK, MY and BZ, and a top-up scholarship for VK (RSRT6016).

Competing interests None declared.

Patient consent for publication Not required.

Ethics approval This study adhered to the Declaration of Helsinki and ethics approval was provided by the Human Research Ethics Committee of the South Eastern Sydney Local Health District (Reference No.: 17/231) and a waiver of consent requirements was provided.

Provenance and peer review Not commissioned; externally peer reviewed.

Data availability statement Data are available on reasonable request. Summary data sets presented in the publication can be accessed on request. Individual data cannot be shared as per patient confidentiality agreements.

Supplemental material This content has been supplied by the author(s). It has not been vetted by BMJ Publishing Group Limited (BMJ) and may not have been peer-reviewed. Any opinions or recommendations discussed are solely those of the author(s) and are not endorsed by BMJ. BMJ disclaims all liability and responsibility arising from any reliance placed on the content. Where the content includes any translated material, BMJ does not warrant the accuracy and reliability of the translations (including but not limited to local regulations, clinical guidelines, terminology, drug names and drug dosages), and is not responsible for any error and/or omissions arising from translation and adaptation or otherwise.

Open access This is an open access article distributed in accordance with the Creative Commons Attribution Non Commercial (CC BY-NC 4.0) license, which permits others to distribute, remix, adapt, build upon this work non-commercially, and license their derivative works on different terms, provided the original work is properly cited, appropriate credit is given, any changes made indicated, and the use is non-commercial. See: http://creativecommons.org/licenses/by-nc/4.0/.

\section{ORCID iDs}

Vincent Khou http://orcid.org/0000-0002-4696-9226

Angelica Ly http://orcid.org/0000-0001-7881-1522
Michael Hennessy http://orcid.org/0000-0003-2750-9344

\section{REFERENCES}

1 Beard JR, Officer A, de Carvalho IA, et al. The world report on ageing and health: a policy framework for healthy ageing. Lancet 2016;387:2145-54.

2 Global Burden of Metabolic Risk Factors for Chronic Diseases Collaboration. Cardiovascular disease, chronic kidney disease, and diabetes mortality burden of cardiometabolic risk factors from 1980 to 2010: a comparative risk assessment. Lancet Diabetes Endocrinol 2014;2:634-47.

3 Klein R, Klein BEK. The prevalence of age-related eye diseases and visual impairment in aging: current estimates. Invest Ophthalmol Vis Sci 2013;54:ORSF5.

4 Thompson AC, Thompson MO, Young DL, et al. Barriers to follow-up and strategies to improve adherence to appointments for care of chronic eye diseases. Invest Ophthalmol Vis Sci 2015;56:4324-31.

5 Prasad S, Tanner V, Patel CK, et al. Optimisation of outpatient resource utilisation in cataract management. Eye 1998;12 (Pt 3a:403-6.

6 Stainkey LA, Seidl IA, Johnson AJ, et al. The challenge of long waiting lists: how we implemented a GP referral system for nonurgent specialist' appointments at an Australian public hospital. BMC Health Serv Res 2010;10:303.

7 Thomas HF, Darvell $\mathrm{RH}$. Audit of an ophthalmology waiting list. $\mathrm{Br} \mathrm{J}$ Ophthalmol 1991;75:28-30.

8 Do VQ, McCluskey P, Palagyi A, et al. Are cataract surgery referrals to public hospitals in Australia poorly targeted? Clin Exp Ophthalmol 2018;46:364-70.

9 Huang J, Hennessy MP, Kalloniatis M, et al. Implementing collaborative care for glaucoma patients and suspects in Australia. Clin Exp Ophthalmol 2018;46:826-8.

10 Huang J, Yapp M, Hennessy MP, et al. Impact of referral refinement on management of glaucoma suspects in Australia. Clin Exp Optom 2020;103:675-83.

11 Goetz RK, Hughes FE, Duignan ES, et al. A template for reducing ophthalmology outpatient waiting times: community ophthalmic care. Ir J Med Sci 2018;187:237-41.

12 Ratnarajan G, Newsom W, French K, et al. The impact of glaucoma referral refinement criteria on referral to, and first-visit discharge rates from, the hospital eye service: the Health Innovation \& Education Cluster (HIEC) Glaucoma Pathways project. Ophthalmic Physiol Opt 2013;33:183-9.

13 Tey A, Grant B, Harbison D, et al. Redesign and modernisation of an NHS cataract service (Fife 1997-2004): multifaceted approach. BMJ 2007;334:148-52.

14 Ferrer L, Goodwin N. What are the principles that underpin integrated care? Int J Integr Care 2014;14:e037.

15 Nari J, Allen LH, Bursztyn LLCD. Accuracy of referral diagnosis to an emergency eye clinic. Can J Ophthalmol 2017;52:283-6.

16 Pierscionek TJ, Moore JE, Pierscionek BK. Referrals to ophthalmology: optometric and general practice comparison. Ophthalmic Physiol Opt 2009;29:32-40.

17 Davey CJ, Scally AJ, Green C, et al. Factors influencing accuracy of referral and the likelihood of false positive referral by optometrists in Bradford, United Kingdom. J Optom 2016;9:158-65.

18 Bell RW, O'Brien C. Accuracy of referral to a glaucoma clinic. Ophthalmic Physiol Opt 1997;17:7-11.

19 Davey CJ, Green C, Elliott DB. Assessment of referrals to the hospital eye service by optometrists and GPs in Bradford and Airedale. Ophthalmic Physiol Opt 2011;31:23-8.

20 Blundell N, Clarke A, Mays N. Interpretations of referral appropriateness by senior health managers in five PCT areas in England: a qualitative investigation. Qual Saf Health Care 2010;19:182-6.

21 Su N, Cheang PP, Khalil H. Do rhinology care pathways in primary care influence the quality of referrals to secondary care? J Laryngol Otol 2013;127:364-7.

22 G Pitman A. Quality of referral: what information should be included in a Request for diagnostic imaging when a patient is referred to a clinical radiologist? J Med Imaging Radiat Oncol 2017;61:299-303.

23 Cheng J, Beltran-Agullo L, Trope GE, et al. Assessment of the quality of glaucoma referral letters based on a survey of glaucoma specialists and a glaucoma guideline. Ophthalmology 2014;121:126-33.

24 Davies RF. Waiting Lists for health care: a necessary evil? CMAJ 1999;160:1469-70.

25 Mathias $\mathrm{H}$, Heisler C, Morrison J, et al. Examining the association between referral quality, wait time and patient outcomes for patients 
referred to an IBD specialty program. $J$ Can Assoc Gastroenterol 2020;3:154-61.

26 Nash E, Hespe C, Chalkley D. A retrospective audit of referral letter quality from general practice to an inner-city emergency department. Emerg Med Australas 2016;28:313-8.

27 Queensland Government. Waiting lists [Internet]. Brisbane, Australia: Queensland Government, 2015. Available: https://www.qld.gov.au/ health/services/hospital-care/waiting-lists

28 Victorian Agency for Health Information. Patients treated by urgency category $(1,2,3)$ [Internet]. Melbourne, Australia: Victoria State Government, 2021. Available: https://vahi.vic.gov.au/electivesurgery/patients-treated-urgency-category-123

29 New South Wales Health. Outpatient services framework [Internet]. Sydney, Australia: New South Wales Health, 2019. Available: https:// www1.health.nsw.gov.au/pds/ActivePDSDocuments/GL2019_011. pdf

30 Donald S. Your chi-square test is statistically significant: now what? Pract Assess Res Evaluation 2015;20:1-10.

31 Greenwood-Lee J, Jewett L, Woodhouse L, et al. A categorisation of problems and solutions to improve patient referrals from primary to specialty care. BMC Health Serv Res 2018;18:986.

32 Tam HL, Chung SF, Lou CK. A review of triage accuracy and future direction. BMC Emerg Med 2018;18:58.
33 Leinonen J, Laatikainen L. The decrease of visual acuity in cataract patients waiting for surgery. Acta Ophthalmol Scand 1999;77:681-4.

34 Wåhlberg H, Valle PC, Malm S, et al. Impact of referral templates on the quality of referrals from primary to secondary care: a cluster randomised trial. BMC Health Serv Res 2015;15:353.

35 French JA, Stevenson CH, Eglinton J, et al. Effect of information about waiting Lists on referral patterns of general practitioners. $\mathrm{Br} J$ Gen Pract 1990;40:186-9.

36 Nancarrow SA, Booth A, Ariss S, et al. Ten principles of good interdisciplinary team work. Hum Resour Health 2013;11:19.

37 Ophthalmology Network. Business rules for ophthalmology clinics. Chatswood, NSW, Australia: Agency for Clinical Innovation, 2019.

38 Felfeli T, Christakis PG, Bakshi NK, et al. Referral characteristics and wait times for uveitis consultation at academic tertiary care centres in Toronto. Can J Ophthalmol 2018;53:639-45.

39 Tahhan N, Ford BK, Angell B, et al. Evaluating the cost and waittimes of a task-sharing model of care for diabetic eye care: a case study from Australia. BMJ Open 2020;10:e036842.

40 Ford BK, Kim D, Keay L, et al. Glaucoma referrals from primary care and subsequent hospital management in an urban Australian hospital. Clin Exp Optom 2020;103:821-9. 